\title{
Verification of Integrity of Steam Generator Tubes by
}

\section{Pressure Testing}

\author{
Yong-Seok Kang ${ }^{1}$, Min-Woo Nam ${ }^{1}$ and Jai-Hak Park ${ }^{2}$ \\ 1. Central Research Institute of Korea Hydro \& Nuclear Power Co., Daejeon 305-343, South Korea \\ 2. Department of Safety Engineering, Chungbuk National University, Cheongju 361-763, South Korea
}

Received: May 03, 2013 / Accepted: July 09, 2013 / Published: December 31, 2013.

\begin{abstract}
This paper assessed the benefit of the in-situ pressure test to support steam generator tube integrity assessment and reviewed a conservatism of currently applied structural integrity assessment methodology against defected tubes. According to the steam generator program requirement, condition monitoring assessment was performed to the all detected flaws. For condition monitoring assessments, the limiting structural integrity requirement should be demonstrated for all detected degraded tubes at a probability of at least 0.95 at $50 \%$ confidence. Some flaws were slightly exceeded the structural integrity threshold values of the condition monitoring performance limits using analytical method. As a direct evaluation of tube integrity with degraded tubes, in-situ pressure testing performed on some selected flaws and passed all proof and leakage test criteria with no leakage. From this pressure testing, the authors have verified that degraded tubes met a specified value containing a defined safety margins. Also, the authors have confirmed that existing structural assessment methodology has enough margins to retain integrity of steam generator tubes.
\end{abstract}

Key words: Pressure testing, steam generator tube, integrity assessment.

\section{Introduction}

A steam generator tube is one of pressure retaining components of reactor cooling system in nuclear power plants. Therefore, all tubes should be monitored and maintained carefully to address their integrity during the normal and accident operating condition.

In-service inspection by using eddy current testing has performed to steam generators of nuclear power plants during the refueling outage. From the inspection results, some large flaws such as stress corrosion cracking were identified. All detected degradation shall be evaluated to demonstrate their integrity by analytical method. However, several large flaws were exceeded the specified integrity performance criteria. The leakage performance criteria could meet the requirement but the structural criteria could not meet its threshold value. Steam generator

Corresponding author: Yong-Seok Kang, principal researcher, research field: steam generator management. E-mail: kysme@khnp.co.kr. management program of EPRI (Electric Power Research Institute) suggests three kinds of method such as analytical calculation, laboratory tests with pulled tubes and in-situ testing, to demonstrate that condition monitoring requirements are met [1]. Generally, analytical calculation with eddy current inspection result to characterize the flaw is an economic but it can lead to overly conservative assessment to detected flaws. Laboratory test with pulled tubes contains inherent cost and potential uncertainties associated with pulling tubes for testing. Therefore, direct pressure testing method such as in-situ pressure testing was applied to demonstrate their integrity specified in plant technical specifications.

In this paper, the authors have introduced the benefits of the in-situ pressure testing to support steam generator tube integrity assessment and reviewed a conservatism of structural integrity assessment methodology against degraded tubing. 


\section{Steam Generator Tube Integrity and In-service Inspection}

\subsection{Steam Generator Tube Performance Criteria}

NEI 97-06 [2] provides the fundamental elements such as performance criteria for steam generator program. Meeting the performance criteria provides reasonable assurance that steam generator tubing remains capable of fulfilling its specific safety function of maintaining reactor cooling system pressure boundary integrity. The structural integrity performance criterion is: All in-service steam generator tubes shall retain structural integrity over the full range of normal operating conditions and design basis accidents. This includes retaining a safety factor of 3.0 against burst under normal steady state full power operation primary-to-secondary pressure differential and a safety factor of 1.4 against burst applied to the design basis accident primary-to-secondary pressure differentials.

The condition monitoring assessment requires that the detected flaws, as determined by in-service inspection, do not exceed the appropriate condition monitoring limit for each degradation mechanism.

The condition monitoring limit is obtained by modifying the structural limit to account for uncertainties associated with the tube failure regression model, material properties and the non-destructive examination system as shown in Fig. 1 [3]. The requirement for condition monitoring is that the observed worst-case degraded case tube will exhibit, via non-destructive examination sizing and analysis or in-situ testing, a minimum burst pressure that meets structural integrity performance criteria. The worst-case degraded tube is established from the estimation of lower extreme values of structural performance parameters representative of all degraded tubes in the bundle [4]. Fig. 2 illustrates typical condition monitoring limit curve for axial flaws.

Laboratory test with pulled tubes could be determined more exact solution than analytical calculations of burst pressure or in-situ testing of

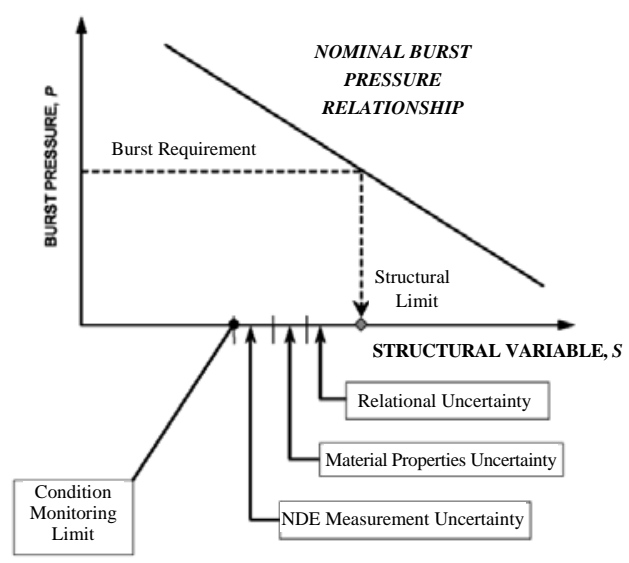

Fig. 1 Condition monitoring elements of tube integrity assessment.

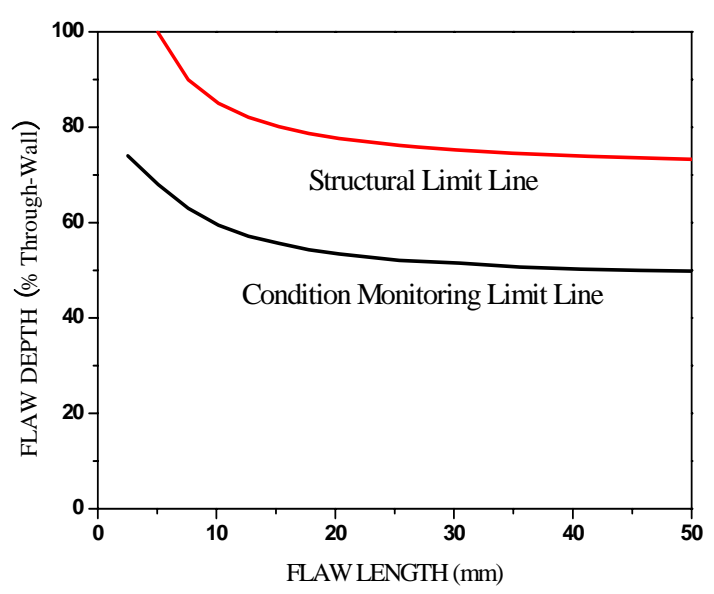

Fig. 2 Typical condition monitoring limit for axial flaw.

sections of tubing with eddy current indications of degradation. However, laboratory test with pulled tubes is regarded as an unfavorable method in the financial aspect. If analytical calculation results could not meet the required performance criteria then the direct evaluation such as in-situ pressure testing could be good corrective actions to support condition monitoring assessment. A schematic relationship between integrity assessment and in-situ pressure test is shown in Fig. 3.

\subsection{In-service Inspection Results on Steam Generator Tubes}

To verify steam generator tube integrity in accordance with the steam generator management program requirements, in-service inspection of steam generator tubes was conducted using qualified 


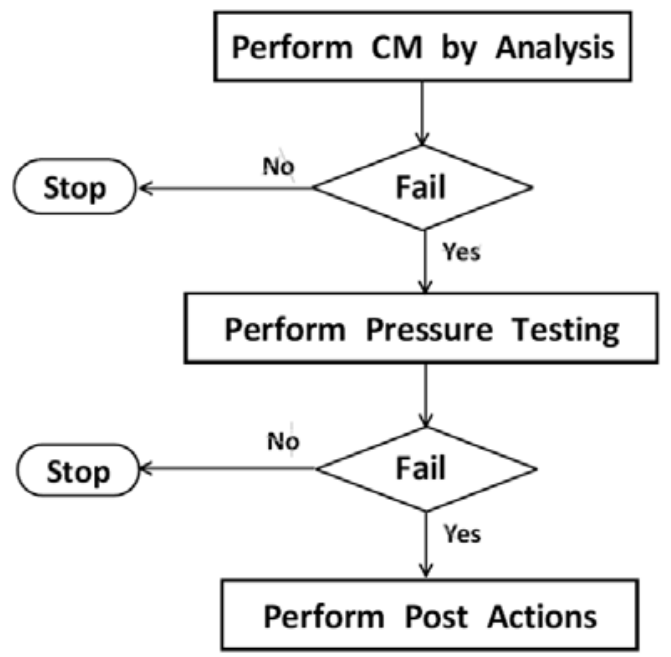

Fig. 3 In-situ pressure testing flowchart.

techniques capable of detecting and characterizing the degradation mechanisms. According to the steam generator examination guidelines [5, 6], 100\% full length examination was performed using bobbin coil probe. When abnormal signals such as distorted support signals at tube support plates were detected then post supplemental test using motorized plus point probe was performed. In addition, history review process was applied to determine if this abnormal signal is a flaw or not. From the evaluation, many abnormal signals specially detected within the tube support plates were classified as an axial outer diameter stress corrosion cracking. A sample of motorized rotating coil signal is shown in Fig. 4. In this case, the flaw was detected at the 8th tube support plate of hot-leg side and classified as a SAI (single axial indication).

\subsection{Condition Monitoring Evaluation}

For verification of structural integrity during the preceding cycle of operation, all indication of flaws evaluated to meet the appropriate limiting structural integrity performance parameter with probability of 0.95 at 50\% confidence level, including consideration of a relative uncertainty. All exceeding condition monitoring limits flaws are axial flaws. The geometry of flaw for integrity assessment is parallel to the axis of the tube and surface flawed. A typical geometry of

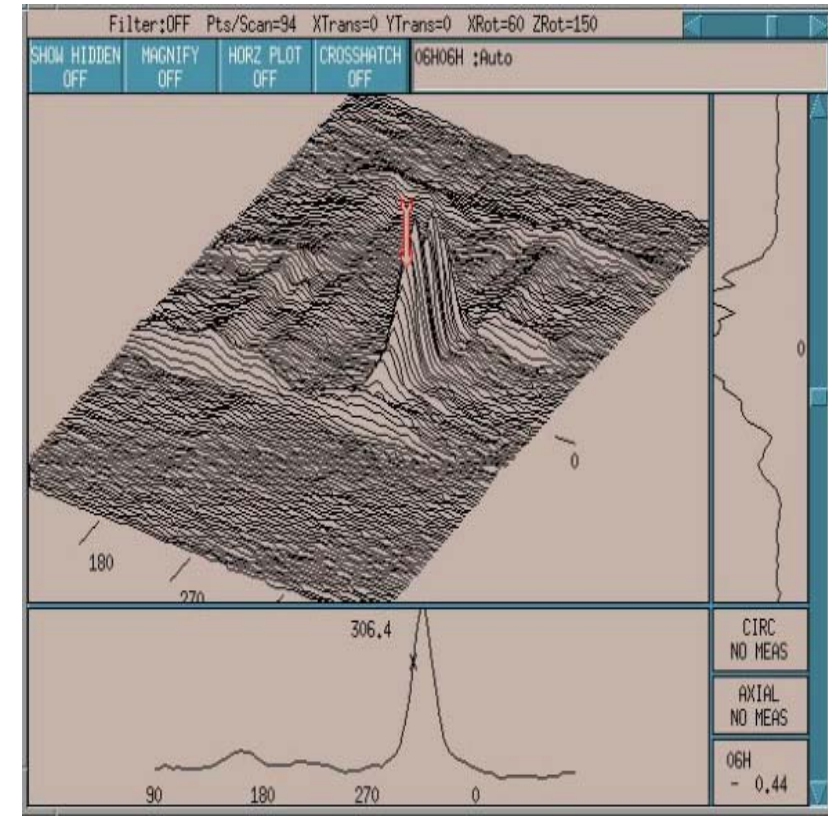

Fig. 4 A sample eddy current test signal to axial flaw.

the degradation is illustrated in Fig. 5. All detected flaws were evaluated obtaining maximum amplitude, depth and length including crack profiles.

For an integrity assessment to the axial flaws, evaluation of crack profile by plus point rotating coil was conducted. The effective structural depth and effective structural length of predominantly axial degradation are the combination of those variables consistent with segments of the degradation depth profile that leads to the minimum estimate of the burst pressure. The schematic diagram of weak link crack profile for part through-wall axial crack is shown, Fig. 6.

Cothron [7] provides an appropriate equation for axial flaws in straight section of steam generator tubing. All detected flaws from the in-service inspection were not through-wall but part through-wall. The burst pressure equation, for the best average burst pressure as a function of wall thickness, $t$, inner radius, $R_{i}$, effective crack length, $L$, effective structural depth, $d$, and relative effective structural depth, $h=d / t$, is

$$
P_{B}=\Phi \cdot 0.58\left(S_{y}+S_{u}\right) \frac{t}{R_{i}}\left[1.104-\frac{L}{L+2 t} h\right]
$$

where, $\Phi$ is 1.0 for outer diameter cracking. The coefficient 1.104 is a mean value from burst test results 


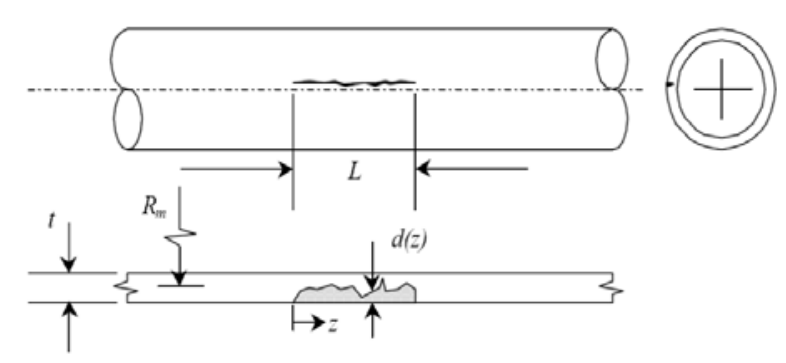

Fig. 5 Geometry of part through-wall crack.

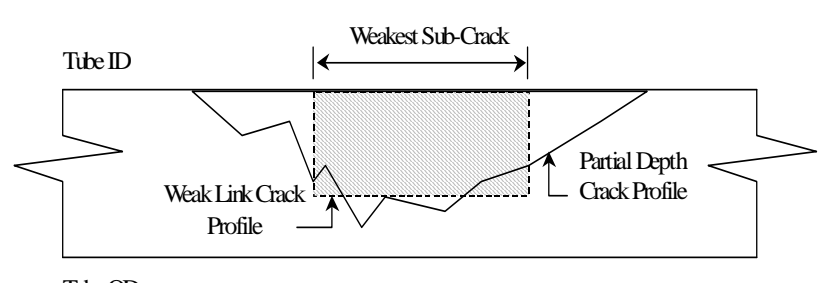

Tube OD

Fig. 6 Part through-wall axial flaw profile with the weak link profile.

on pulled tubes and calculations. The distribution may be to be normal. The condition monitoring structural limit is a description of the limiting set of measured characterizing parameters meeting a given minimum burst pressure with a probability of 0.95 at $50 \%$ confidence level.

The combination of the material strength, the burst relation, the length and the depth uncertainties were developed numerically by Monte Carlo simulations. From the evaluation results to the defected tubes, some flaws exceeded the structural integrity threshold values of condition monitoring performance limits. In this case, we could not verify integrity of degraded tubes by using analytical calculation methods. An eddy current inspection results to characterize the flaw is an economic but it has several uncertainties in sizing degraded regions. Therefore, it can lead to overly conservative assessment of the detected degradation. As a corrective action, in-situ pressure testing was introduced. The benefits of direct evaluation of the structural of degraded sections of tubing can be realized with in-situ pressure testing. In-situ pressure testing refers to hydraulic pressure tests performed on installed tubing in the field.

All flaws were screened for both leakage and proof testing. If the indication only fails screening for structural integrity, a leak test is also required. Tube selection was based on consideration of the eddy current examination results. Maximum voltage, crack length, crack depth and average depth are regarded as parameters for screening.

\section{Application of In-situ Pressure Testing}

\subsection{Test Equipments for Pressure Testing}

In-situ pressure testing was carried out on indications that met in-situ pressure test criteria and complied with the requirements of Ref. [8]. Due to all location of indications which met in-situ pressure test criteria was within tube support plates, local test process was applied. Figs. 7-9 show pressure testing equipments. The tool was inserted into the degraded tube and short section of tube was pressurized and the test area was sealed therefore only the area of interest was exposed to the test pressure. The upper seal bladder was located over the defect to prevent leakage. The hydraulic pump for in-situ pressure testing could pressure up to $68.95 \mathrm{MPa}$ (10,000 psi). Simplified specifications of test equipments are listed in Table 1.

\subsection{Test Sequence Plan and Results}

A leak test on the equipment was performed to the maximum test pressure to account for system leakage prior to testing any defect. During the testing, the minimum hold time was 2 min at approximately every 3.45 MPa (500 psi) or less. Pressurizing began from the adjusted normal operating differential pressure and the maximum test pressure was set at three times against burst under normal steady state full power operation primary-to-secondary pressure differential with test hold at normal operating differential pressure, main steam line break, and at 3.45 MPa (500 psi) intermediate pressure increments. Pressurization rates maintained at less than 1.38 MPa (200 psi) per second, as averaged over the time interval for pressurization to each hold point.

The material properties of tubes in-situ tested can vary from tube-to-tube or steam generator-to-steam 


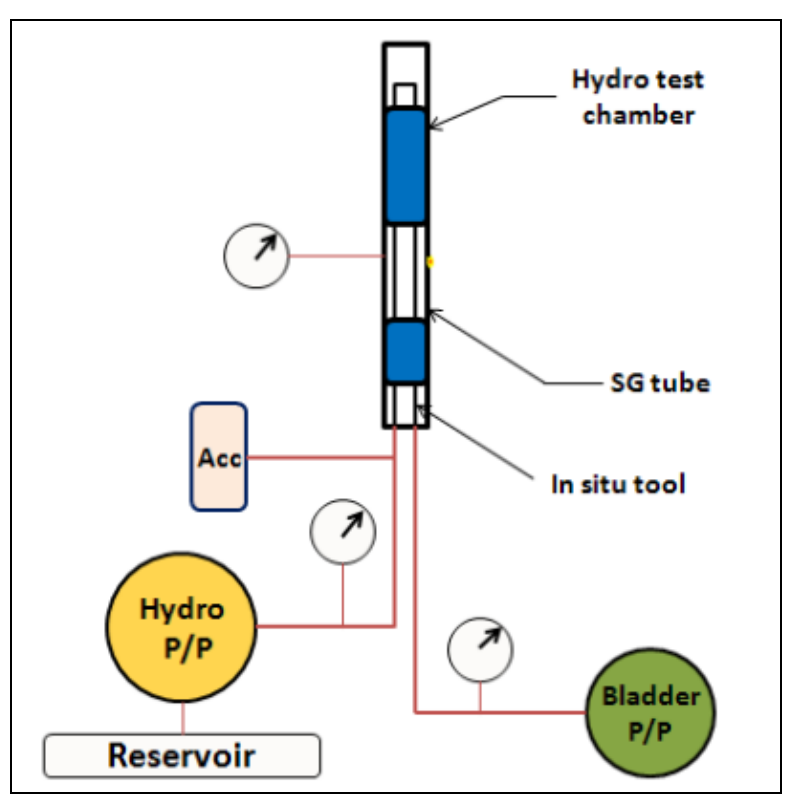

Fig. 7 Layout of pressure testing system.

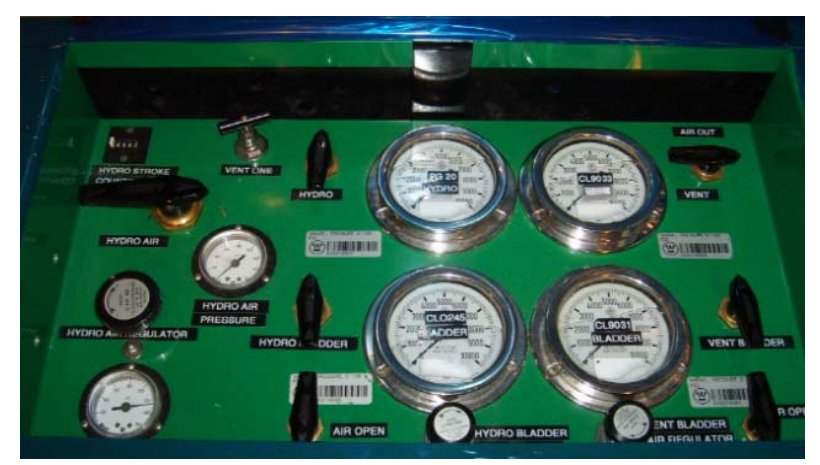

Fig. 8 In-situ testing controller and gauges.

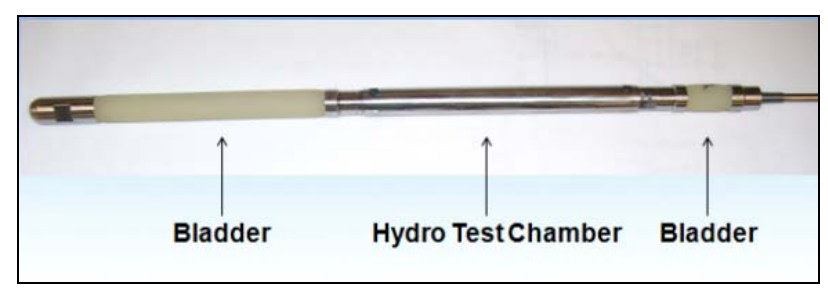

Fig. 9 Probe for pressure testing.

Table 1 Description for test equipments.

\begin{tabular}{ll}
\hline Equipments & Specifications \\
\hline Hydraulic pump & $68.95 \mathrm{MPa}, 10 \mathrm{~m}^{3} / \mathrm{min}$ \\
DAS (data acq. system) & Data acquisition controller \\
Personal computer & WINDAQ system \\
\hline
\end{tabular}

generator and therefore the proof and leak test results can be adjusted to account for these differences. In this test, actual properties of the tube room temperature on manufacturers' test data of tubing materials were included. To take into consideration of temperature effects, flow strength ratio for elevated $343{ }^{\circ} \mathrm{C}$ $\left(650^{\circ} \mathrm{F}\right), 1.08$ [8] was included.

Actual test results are listed in Table 2. To obtain a target structural integrity test pressure, some adjustments including the material strength temperature correction and the pressure gage uncertainty are made to the three times against burst under normal steady state full power operation primary-to-secondary pressure differential value of 26.36 MPa. Due to the sensitivity of the pressure testing equipment handling, exact pressure setting was not easy. Therefore, actual testing pressure was slightly different to all tested tubes but the level of difference was ignorable. There was no leakage and no burst during the test up to target pressure.

Fig. 10 is a sample pressure recording during the in-situ pressure testing. The red line indicates a hydraulic pump pressure and the black line shows a seal bladder pump pressure. The test pressure increased except for holding points at normal operating differential pressure, intermediate proof test pressure and arrived at target pressure. Post test verification of calibration has performed prior to termination of in-situ testing to verify that equipment performance did not degraded and results are still valid. Fig. 11 shows calibration test results.

From this test, we have confirmed that the test results have a validation. To review pressurizing influence to the flaws, eddy current testing such as rotating coil probe inspection on the flaw that was in-situ pressure tested was performed. Post test results are compared to pre test data in following Table 3. All of the signal amplitudes were increased after the testing however less than critical voltage for leakage, $3.3 \mathrm{~V}$, which is threshold peak-to-peak voltage that corresponds to a potential large leak and/or a high probability of leakage under limiting accident condition for the detected degradation [9].

Also, crack profile changes are compared to pre test and the results are shown in Figs. 12-14. All flaws 
Table 2 Pressure testing results.

\begin{tabular}{|c|c|c|c|c|c|}
\hline \multirow{2}{*}{$\begin{array}{l}\text { Target } \\
\text { pressure } \\
\text { (MPa) }\end{array}$} & \multicolumn{3}{|c|}{ est Actual test pressure (MPa) } & \multirow{2}{*}{$\begin{array}{l}\text {-Burst, } \\
\text { leak }\end{array}$} & \multirow{2}{*}{ Remark } \\
\hline & Tube 1 & Tube 2 & Tube 3 & & \\
\hline 8.78 & 9.58 & 9.51 & 9.51 & No & NODP \\
\hline 11.03 & 11.72 & 11.72 & 11.72 & No & \\
\hline 11.91 & 12.76 & 12.76 & 12.76 & No & MSLB \\
\hline 15.17 & 15.86 & 15.93 & 15.86 & No & \\
\hline 17.93 & 18.62 & 18.62 & 18.62 & No & \\
\hline 20.68 & 21.37 & 21.37 & 21.44 & No & \\
\hline 23.44 & 24.13 & 24.13 & 24.13 & No & \\
\hline 26.36 & 27.17 & 27.58 & 27.17 & No & 3NODP \\
\hline
\end{tabular}

NODP—normal operating differential pressure; MSLB-main steam line break; 3NODP — three times against NODP.

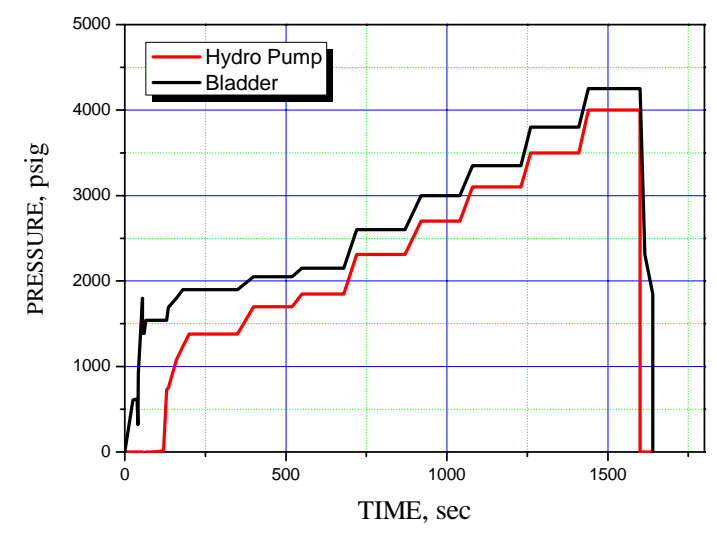

Fig. 10 Pressure trend during pressurizing.

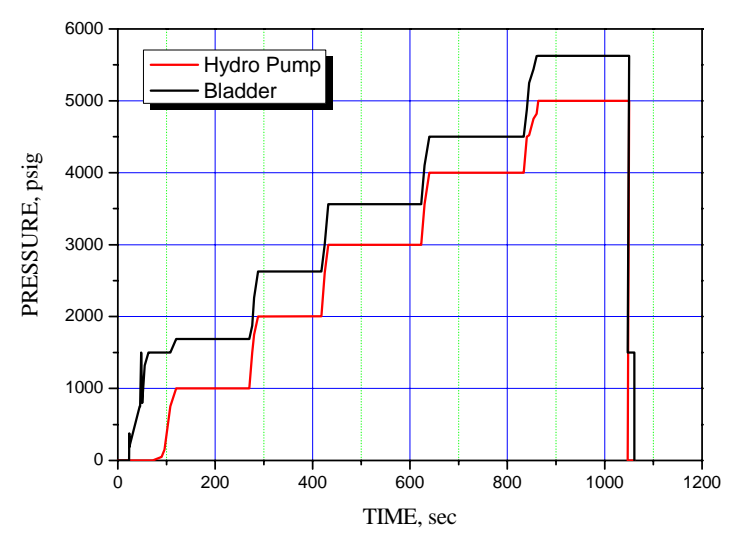

Fig. 11 Calibration test results.

Table 3 Comparison of pressure testing impact.

\begin{tabular}{lllllll}
\hline \multirow{2}{*}{$\begin{array}{l}\text { Tube } \\
\text { No. }\end{array}$} & \multicolumn{3}{c}{ Pre-test } & \multicolumn{3}{c}{ Post-test } \\
& (V) & $\begin{array}{l}\text { Depth } \\
\text { (\%TW) }\end{array}$ & $\begin{array}{l}\text { Length } \\
(\mathrm{mm})\end{array}$ & $(\mathrm{V})$ & $\begin{array}{l}\text { Depth } \\
(\% \mathrm{TW})\end{array}$ & $\begin{array}{l}\text { Length } \\
(\mathrm{mm})\end{array}$ \\
\hline 1 & 1.4 & 69.0 & 42.9 & 1.58 & 72.0 & 43.4 \\
2 & 1.3 & 69.0 & 22.1 & 1.63 & 73.0 & 22.1 \\
3 & 0.8 & 54.0 & 36.2 & 0.9 & 59.0 & 43.7 \\
\hline
\end{tabular}

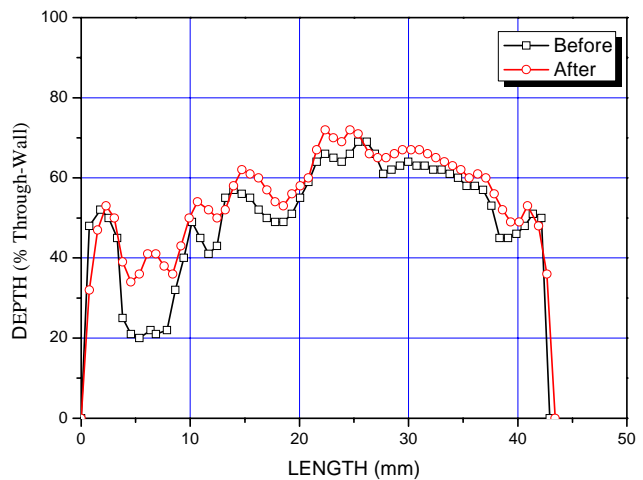

Fig. 12 Crack profiling plots (1).

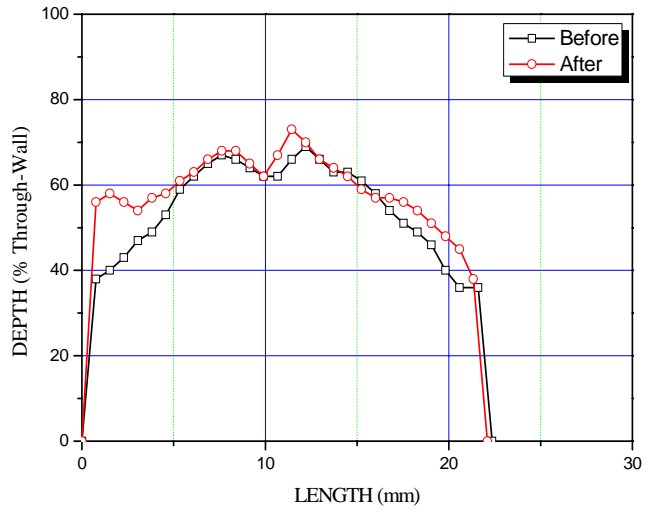

Fig. 13 Crack profiling plots (2).

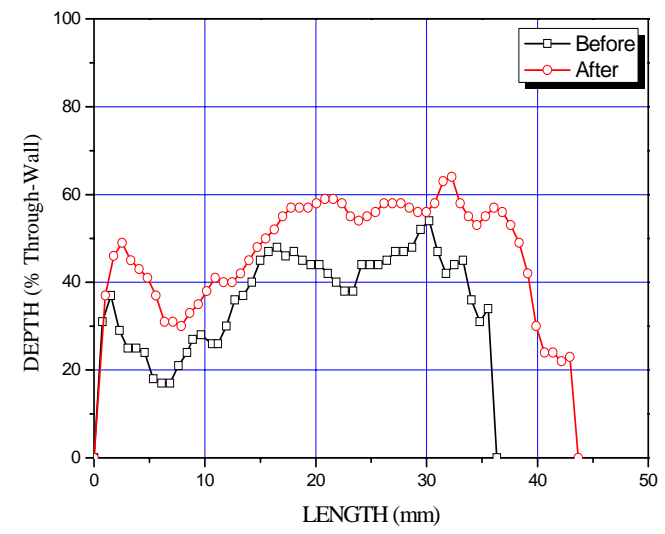

Fig. 14 Crack profiling plots (3).

showed that depth and length of all indications increased slightly. All detected flaw is generated at normal operating differential pressure conditions, 8.14 MPa (1,180 psi), and by the proof test its pressure loading was increased up to over than three times normal operating differential pressure. However, significant change of flaw sizing and signal amplitude was not shown. 
All tested indications achieved pressure demonstrating that structural performance criteria were satisfied and proof testing was terminated. From this in-situ test results we have demonstrated that condition monitoring structural and leakage integrity performance criteria are satisfied. When eddy current testing and analytical evaluation could not verify required performance criteria then in-situ pressure is a good alternative option. Also, even if indications are exceeding the calculated condition monitoring limit, it also could have a required safety margins. In other words, currently being applied integrity assessment methodology could be regarded as a conservative assessment methodology.

\section{Conclusions}

In-service inspection results showed that some flaws exceed the designated condition monitoring criterion to the axial stress corrosion cracking. In-situ pressure testing performed on indications to verify structural margins in instances where flaws non-destructive examination parameters have exceeded minimum structural integrity threshold values. Pressure test passed all proof test criteria with no burst and leakage. Therefore, the authors have ensured that required structural margins are maintained with all indications.
In addition, the authors have confirmed that existing structural assessment methodology has enough margins to retain integrity of steam generator tubes. The benefit of direct evaluation of the strength of degraded sections of tubing was realized with in-situ pressure testing.

\section{References}

[1] H. Cothron, Steam Generator Management Program: Steam Generator In-Situ Pressure Test Guidelines Rev. 4, EPRI report, 2012, pp. 1-1.

[2] NEI 97-06, Steam Generator Program Guidelines Rev. 3, Nuclear Energy Institute, 2011, pp. 7-11.

[3] H. Cothron, Steam Generator Integrity Assessment Guidelines Rev. 3, EPRI report, 2009, pp. 3-2-3-3.

[4] H. Cothron, Steam Generator Integrity Assessment Guidelines Rev. 3, EPRI report, 2009, pp. 2-3-2-4.

[5] Integrated Guidelines of Steam Generator Management Program of KHNP Rev. 2, SG Inspection, 2013, pp. 15.

[6] S. Swilley, Steam Generator Management Program: Pressurized Water Reactor Steam Generator Examination Guidelines Rev. 7, EPRI report, 2007, pp. 3-3.

[7] H. Cothron, Steam Generator Management Program: Steam Generator Degradation Specific Management Flaw Handbook Rev. 1, EPRI report, 2009, pp. 5-14-5-21.

[8] H. Cothron, Steam Generator Management Program: Steam Generator in Situ Pressure Test Guidelines Rev. 4, EPRI report, 2012, pp. 9-15.

[9] Integrated Guidelines of Steam Generator Management Program of KHNP Rev. 2, SG In-situ Pressure Testing, 2013, pp. 11. 